\title{
Association between beta-blocker use and obesity in Hong Kong Chinese elders: a post-hoc analysis
}

\author{
KL Leung, Winnie Fong, Ben Freedman, Beata Bajorek, Vivian WY Lee *
}

\section{A B S T R A C T}

Introduction: Studies of Caucasian populations have shown that beta-blockers may exacerbate weight gain, a risk factor for many chronic diseases. Still, beta-blockers are the most prescribed antihypertensives in the Chinese population in Hong Kong. We aimed to explore the association between beta-blocker use, hypertension, and weight status of this population.

Methods: A post-hoc analysis regarding body mass index (BMI) and the use of beta-blockers was performed based on the medication profile of community-dwelling older adults. Participants' BMI, hypertension diagnosis, name, dose, frequency, route of administration of beta-blockers, and other drugs that may alter body weight were recorded.

Results: Of 1053 Chinese individuals aged $\geq 65$ years (mean age $76.9 \pm 7.2$ years, $80 \%$ female) from 32 elderly centres in Hong Kong, 18\% (185/1053) of them consumed beta-blockers. That group also had a significantly larger proportion of obese individuals (45.9\% vs $32.1 \%, \mathrm{P}=0.002$ ). After adjusting for other weight-altering drugs, beta-blockers remained a significant predictor of overweight and obesity $(\mathrm{P}=0.001)$. As the hypertensive population had

This article was published on 22 Jan 2020 at www.hkmj.org. significantly higher BMI than the normotensive population $(24.3 \pm 3.6$ vs $22.9 \pm 3.5, \mathrm{P}<0.001)$, a subanalysis on those with hypertension diagnosis confirmed that only the hypertensive population taking atenolol had a significantly larger population of obese individuals (BMI $\geq 25$ ) compared with those who took metoprolol (58.9\% vs $38.5 \%, \mathrm{P}=0.03)$ and those who did not take any beta-blockers $(58.9 \%$ vs $38.4 \%, \mathrm{P}=0.007)$.

Conclusions: Our findings taken together with other guideline reservations cast doubt on whether betablockers, particularly atenolol, should be the major drug prescribed to older adults with hypertension.

\section{Hong Kong Med J 2020;26:27-34 \\ https://doi.org/10.12809/hkmj198077}

${ }^{1} \mathrm{KL}$ Leung, BPharm, BSc

${ }^{1}$ W Fong, BPharm

${ }^{2}$ B Freedman, MB, BS, PhD

${ }^{3}$ B Bajorek, PhD, BPharm

${ }^{4}$ VWY Lee *, PharmD, BCPS

School of Pharmacy, Faculty of Medicine, The Chinese University of Hong Kong, Shatin, Hong Kong

Heart Research Institute, Charles Perkins Centre, University of Sydney, Sydney, Australia

Graduate School of Health, University of Technology Sydney, Sydney, Australia

${ }^{4}$ Centre for Learning Enhancement And Research, The Chinese

University of Hong Kong, Shatin, Hong Kong

* Corresponding author: vivianlee@cuhk.edu.hk

New knowledge added by this study

- Beta-blocker consumption is associated with obesity in Chinese older adults.

- Hypertensive population taking atenolol had the largest portion of obesity.

- Strong and unique association of obesity and atenolol usage.

Implications for clinical practice or policy

- Healthcare professionals should be more vigilant concerning initiation of therapy for hypertension and ongoing surveillance of weight, such as carefully assessing baseline characteristics (including both body mass index and blood pressure status) before prescribing a beta-blocker, and regular monitoring of both parameters in hypertension treatment, particularly for patients with obesity and those who have not yet become obese if betablockers are prescribed.

\section{Introduction}

Hypertension is highly prevalent and a key risk factor for cardiovascular disease. ${ }^{1}$ Less well recognised by patients and health professionals alike is that some of the pharmacotherapies used to treat hypertension may adversely impact other cardiovascular risk factors by causing weight gain.
More specifically, the weight gain effects of betaadrenergic antagonists (beta-blockers) have been highlighted by many studies of Caucasian patients. ${ }^{2-5}$ Many guidelines no longer list beta-blockers as first-line antihypertensives. ${ }^{6-8}$ However, the 2018 hypertension guidelines published by the European Society of Cardiology and the European Society of 


\section{華籍香港長者使用 $\beta$ 受體阻滯劑與肥胖間的 關聯：事後比較分析}

梁健麟、房穎儀、Ben Freedman、Beata Bajorek、李詠恩

引言：西方人口的研究顯示 $\beta$ 受體阻滯劑可能加劇體重增加, 而體重 增加是許多慢性疾病的危險因素。 $\beta$ 受體阻滯劑仍是香港華籍患者中 最常處方的降壓藥。本研究旨在探討 $\beta$ 受體阻滯劑的使用、高血壓與 該人群體重狀況間的關係。

方法：根據社區居民長者的用藥情況, 對受試者的體重指數（BMI） 和使用 $\beta$ 受體阻滞劑進行事後比較分析。記錄他們的BMI、高血壓診 斷、 $\beta$ 受體阻滞劑名稱、劑量、使用頻率和給藥途徑, 以及其他可能 改變體重的藥物。

結果：來自香港 32 間老年中心共 1053 名 65 歲或以上華人受試者中 （平均年齡76.9 57.2 歲，女性佔 $80 \%$ ），18\%（185/1053）服用 $\beta$ 受體阻滯劑。該組的肥胖個體比例也明顯較高 $(45.9 \%$ 比 $32.1 \%$, $\mathrm{P}=0.002 ） 。$ 對其他改變體重的藥物因素作出調整後, $\beta$ 受體阻滞劑仍 是超重和肥胖的重要預測指標 $(\mathrm{P}=0.001)$ 。由於高血壓人群的BMI 顯著高於正常人群 $(24.3 \pm 3.6$ 比 $22.9 \pm 3.5, \mathrm{P}<0.001)$, 對高血壓 診斷對象的亞分析證實, 服用阿替洛爾的高血壓人群其肥胖人群 (即 $\mathrm{BMI} \geq 25$ ）明顯多於服用美托洛爾（ $58.9 \%$ 比 $38.5 \% ， \mathrm{P}=0.03 ）$ 和未服 用任何 $\beta$ 受體阻滯劑的高血壓人群 $(58.9 \%$ 比 $38.4 \%, \mathrm{P}=0.007)$

結論：研究結果與其他指南保留意見皆令人懷疑 $\beta$ 受體阻滯劑（尤其 是阿替洛爾）是否應作為老年高血壓患者的主要處方藥。
Hypertension, ${ }^{9}$ the joint statement published in 2012 by the European Society of Hypertension and the European Association for the Study of Obesity, ${ }^{10}$ and a position paper of The Obesity Society and the American Society of Hypertension ${ }^{11}$ still advocate the use of beta-blockers in patients with both hypertension and obesity because beta-blockade is more effective in lowering blood pressure (BP) in patients with obesity than in patients who are thinner. ${ }^{12}$ In Hong Kong, two recent large database studies found that beta-blockers are still the most commonly prescribed antihypertensives, although they are used relatively less in younger patients aged $<55$ years. ${ }^{13,14}$ Furthermore, only $4 \%$ of Hong Kong patients have their antihypertensive treatment upgraded by changing from beta-blockers to firstline agents. ${ }^{15}$

The generally increasing prevalence of obesity among older adults is an important factor in drug-induced weight gain. ${ }^{16}$ Studies have shown that obesity in older people is associated with functional impairment and co-morbidity, including hypertension, type 2 diabetes, coronary heart disease, heart failure, and dementia. ${ }^{17-19}$ These chronic conditions, for which being overweight is a risk factor, are also worryingly increasing in prevalence. ${ }^{20-22}$ This renders weight management in older persons an important health issue.

To date, there has been a lack of research to confirm the weight gain effects of beta-blockers in
non-Caucasian populations, and this is particularly germane because so many older Chinese patients with hypertension are still receiving beta-blocker therapy.

The objective of this study was to explore the association between beta-blocker use, hypertension, and overweight/obesity in a cohort of older Chinese people. The specific objectives were to: (1) identify the proportion of patients prescribed beta-blockers; (2) compare the body mass index (BMI) of betablocker users with non-users; and (3) compare the effects of different beta-blockers on BMI.

\section{Methods}

\section{Study design}

A post-hoc analysis was undertaken using an existing dataset comprising the medication profiles of a cohort of community-dwelling older adults in Hong Kong. The data were originally collected (July to August in 2016) for a primary study seeking to explore the relationship between diet and the prevalence of atrial fibrillation. ${ }^{23}$ The study was approved by the Survey and Behavioural Research Ethics Committee of The Chinese University of Hong Kong and was conducted in accordance with the Declaration of Helsinki. Written informed consent was obtained from all study participants. Confidentiality agreement forms were signed by all data collectors. STROBE reporting guidelines were implemented in this manuscript.

\section{Study population}

The original study cohort comprised 1665 people attending one of 32 neighbourhood elderly recreational community centres in Hong Kong. The inclusion criteria included those who were Hong Kong Chinese residents, aged $\geq 65$ years, living in the community, and able to speak and understand Cantonese. The exclusion criteria included those with terminal health conditions and/or significant cognitive impairment that would preclude participation because of communication barriers (eg, severe mental illness, dementia).

\section{Data collection}

All primary study data were collected during a summer community outreach programme-a territory-wide medical outreach service in Hong Kong provided by volunteer students from the Faculty of Medicine, The Chinese University of Hong Kong. The data were originally collected via face-toface interviews with the participants in Cantonese and recorded on paper-based questionnaires by trained volunteer students.

At each outreach visit, participants' body weight, height, and BP were measured, BMI calculated, medication profile extracted, and demographic data recorded. Calculated BMIs were 
compared with the Asian BMI classification set indicating that at least $80 \%$ and $95 \%$ of readings by the World Health Organization, in which BMI are within an absolute difference of 5 to $10 \mathrm{~mm} \mathrm{Hg}$ $\geq 23$ and $\geq 25$ are considered as overweight and from each other, respectively ${ }^{25}$ ). The readings were obese, respectively. ${ }^{24}$ A self-reported diagnosis of compared against 2017 American Heart Association hypertension and diabetes was recorded and verified guidelines, ${ }^{6}$ but such readings were not used to against the patient's current medication profile. diagnose hypertension. To ensure accuracy, for each The self-reported diagnosis of hypertension was patient, the BP measurements were repeated after the only evidence to determine whether the patient 10 minutes of rest when the first reading was found had hypertension or not. As part of the logistics to be elevated (ie, BP $>120 / 80 \mathrm{~mm} \mathrm{Hg}$ ). When a and service provided by our outreach, BP was also beta-blocker had been prescribed, the name, dose, measured using an Omron HEM-7011 ${ }^{\mathrm{TM}}$ electronic frequency, and route of administration of the agent blood pressure monitor (Omron Healthcare, Kyoto were additionally recorded. The consumption of Japan), which has an "A/A" performance classification other drugs known to alter body weight was also under British Hypertension Society criteria (ie, recorded and listed in Table 1.

TABLE I. Participants' demographics and characteristics*

\begin{tabular}{|c|c|c|c|}
\hline & $\begin{array}{l}\text { Total population } \\
(n=1053)\end{array}$ & $\begin{array}{l}\text { Using beta- } \\
\text { blockers }(n=185)\end{array}$ & $\begin{array}{l}\text { Not using beta- } \\
\text { blockers }(n=868)\end{array}$ \\
\hline Male sex & 207 (20\%) & $38(21 \%)$ & 169 (19\%) \\
\hline Age (years) & $76.9 \pm 7.2$ & $77.6 \pm 7.0$ & $76.7 \pm 7.2$ \\
\hline $65-74$ & 415 (39\%) & $61(33 \%)$ & $354(41 \%)$ \\
\hline $75-84$ & 470 (45\%) & $92(50 \%)$ & $378(44 \%)$ \\
\hline $85-100$ & $168(16 \%)$ & $32(17 \%)$ & $136(15 \%)$ \\
\hline BMI $\left(\mathrm{kg} / \mathrm{m}^{2}\right)$ & $23.7 \pm 3.6$ & $24.6 \pm 3.7$ & $23.6 \pm 3.6$ \\
\hline \multicolumn{4}{|l|}{ BMI category (WHO Asian classifications) } \\
\hline Underweight $(<18.5)$ & $61(6 \%)$ & $6(3 \%)$ & $55(6 \%)$ \\
\hline Normal $(18.5$ to <23) & $422(40 \%)$ & $59(32 \%)$ & $363(42 \%)$ \\
\hline Overweight (23 to <25) & 206 (20\%) & 35 (19\%) & $171(20 \%)$ \\
\hline Obese $(\geq 25)$ & $364(35 \%)$ & $85(46 \%)$ & $279(32 \%)$ \\
\hline Diagnosis of hypertension (self-reported) & $626(59 \%)$ & 175 (95\%) & $451(52 \%)$ \\
\hline Diagnosis of diabetes (self-reported) & $192(18 \%)$ & $48(26 \%)$ & $144(17 \%)$ \\
\hline \multicolumn{4}{|l|}{ Blood pressure category (2017 AHA/ACC Guideline) } \\
\hline Normal (SBP $<120 \mathrm{~mm} \mathrm{Hg}$ and DBP $<80 \mathrm{~mm} \mathrm{Hg}$ ) & $118(11 \%)$ & $20(11 \%)$ & $98(11 \%)$ \\
\hline Prehypertension (SBP=120-129 mm Hg and DBP <80 mm Hg) & $131(12 \%)$ & $12(7 \%)$ & $119(14 \%)$ \\
\hline $\begin{array}{l}\text { Hypertension stage } 1(\mathrm{SBP}=130-139 \mathrm{~mm} \mathrm{Hg} \text { or } \mathrm{DBP}=80-89 \\
\mathrm{mm} \mathrm{Hg})\end{array}$ & $226(22 \%)$ & $32(17 \%)$ & $194(22 \%)$ \\
\hline Hypertension stage 2 (SBP $\geq 140 \mathrm{~mm} \mathrm{Hg}$ or DBP $\geq 90 \mathrm{~mm} \mathrm{Hg}$ ) & $578(55 \%)$ & $121(65 \%)$ & $457(53 \%)$ \\
\hline \multicolumn{4}{|l|}{ Drug/drug classes associated with weight gain } \\
\hline Insulin & $15(1 \%)$ & $4(2 \%)$ & $11(1 \%)$ \\
\hline Sulfonylureas & $91(9 \%)$ & $26(14 \%)$ & $65(6 \%)$ \\
\hline Corticosteroids & $9(0.9 \%)$ & $3(2 \%)$ & $6(0.7 \%)$ \\
\hline Antipsychotics & $4(0.4 \%)$ & $2(1 \%)$ & $2(0.2 \%)$ \\
\hline Antidepressants & $19(2 \%)$ & $7(4 \%)$ & $12(1 \%)$ \\
\hline Anticonvulsants & $9(0.9 \%)$ & $1(0.5 \%)$ & $8(0.9 \%)$ \\
\hline Anti-parkinsons & $1(0.1 \%)$ & 0 & $1(0.1 \%)$ \\
\hline \multicolumn{4}{|l|}{ Drug/drug classes associated with weight loss } \\
\hline Metformin & $168(16 \%)$ & $43(23 \%)$ & $125(14 \%)$ \\
\hline Loop diuretics & $34(3 \%)$ & $9(5 \%)$ & $25(3 \%)$ \\
\hline Weight-loss antidepressant & $7(0.7 \%)$ & $3(2 \%)$ & $4(0.5 \%)$ \\
\hline
\end{tabular}

Abbreviations: AHA/ACC = American Heart Association/American College of Cardiology; BMI = body mass index; $\mathrm{DBP}=$ diastolic blood pressure; SBP = systolic blood pressure; $\mathrm{WHO}=$ World Health Organization

* Data are shown as No. (\%) or mean \pm standard deviation 


\section{Statistical analysis}

Data handling (data entry, verification, and analysis) was computerised using SPSS (Windows version 23.0; IBM Corp, Armonk [NY], United States). Only the patients with complete drug profiles a nd a ll variables recorded were included. Any incomplete drug profile o $\mathrm{r} \mathrm{m}$ issing $\mathrm{v}$ ariables ( eg, B MI) w ere considered missing data and were not included in the analysis. Independent samples $t$ tests were used to compare BMI values between people taking different $b$ eta-blockers. $B$ inary $l$ ogistic $r$ egression was used to verify the contributions of various drug classes and co-morbidities on a stratified binary BMI parameter (normal and underweight vs overweight and obesity). Chi squared tests were used to detect any significant $d$ ifferences in the pr oportion of patients with high BMI across different $t$ ypes of beta-blockers. A P value of $<0.05$ was considered statistically significant.

\section{Results}

\section{Participant characteristics}

Among the 1665 individuals participating in the summer community outreach programme, data pertaining to 1053 were included in the analysis after screening against the inclusion and exclusion criteria. The $\mathrm{p}$ articipants' d emographics and characteristics are shown in Table 1. People taking beta-blockers were generally heavier (mean BMI 24.6 \pm 3.7 vs $23.6 \pm 3.6, P<0.001$ ). From the perspective of BP measurement readings, around $80 \%$ of the participants $(804 / 1053)$ had elevated BP measurements during the outreach visit; of these, one third (286/804) had no history of hypertension and were not on any medications likely to be used for treating hypertension. The remaining two thirds (518/804) self-reported having hypertension. From the perspective of self-reported hypertension, $81.9 \%$ of those with self-reported hypertension (513/626) had hypertensive readings, and only 6\% (40/626) had normotensive readings; the remaining ones had borderline hypertensive readings (12\%, 73/626).

Overall, 185 (18\%) of the 1053 participants were using one beta-blocker. Among the range of beta-blockers used, atenolol and metoprolol were the most frequently prescribed $(40 \%$ and $53 \%$, respectively), followed by propranolol (5\%) and bisoprolol (2\%). Among the beta-blocker users, the majority $(95 \%, 176 / 185)$ had a self-reported history of hypertension. In those participants with selfreported hypertension who were not using betablockers $(n=451)$, the main antihypertensive agents prescribed were calcium channel blockers (71.3\%), angiotensin-converting enzyme inhibitors $(22.3 \%)$, angiotensin receptor blockers (12.1\%), alphablockers (7.9\%), methyldopa (4.2\%), hydralazine $(1.0 \%)$, and reserpine $(0.2 \%)$.

\section{Body mass index and beta-blocker use}

Overall, 54.1\% (570/1053) of the participants were overweight or obese. The summary of patients' BMI with or without beta-blockers is summarised in Table 2. After adjusting for consumption of various weight-altering drug classes, binary logistic regression showed that beta-blockers were the only drug class that made a significant contribution to stratified BMI status (ie, classification as overweight or obese) [Table 3]. Among those prescribed betablockers $(n=185)$, a significantly higher proportion was either overweight or obese compared with those who were not taking beta-blockers $(n=868)[64.8 \%$ vs $51.8 \%, \mathrm{P}=0.002$; Table 2]. This difference is most evident when comparing the proportion of patients with obesity across beta-blocker users and non-users (45.9\% vs $32.1 \%$, respectively; $\mathrm{P}=0.002$ ).

Participants deemed to have hypertension (based solely on self-reported diagnosis of hypertension plus verification against medication profile, but not on BP measurement during the outreach service) had a significantly higher BMI than those who were normotensive (mean BMIs: $24.3 \pm 3.6$ vs $22.9 \pm 3.5$, respectively; $\mathrm{P}<0.001)$. Although this difference may not be clinically significant, it triggered further sub-analysis on participants with hypertension diagnosis. A sub-analysis on the patients with self-reported diagnosis of hypertension was performed to confirm the association between the use of beta-blockers and BMI (Table 4). Among these participants with self-reported diagnosis of hypertension $(n=626)$, a significantly higher proportion of patients with obesity (BMI $>25)$ was observed in those using atenolol compared with those taking metoprolol ( $58.9 \%$ vs. $38.5 \%, \mathrm{P}=0.031$ ) or those who did not use any beta-blockers $(58.9 \%$ vs $38.4 \%, \mathrm{P}=0.007)$. Those using atenolol had a significantly higher BMI than those who did not use beta-blockers (mean BMIs: $25.3 \pm 3.5$ vs $24.1 \pm 3.6$, $\mathrm{P}=0.01)$.

Binary logistic regression analysis found that loop diuretics were associated with BMI reduction. However, concerning mechanism and indication, loop diuretics function by enhancing salt and water excretion and are clinically used to maintain

TABLE 2. Body mass index distribution of people who were and were not using beta-blockers*

\begin{tabular}{lcc}
\hline & \multicolumn{2}{c}{ Beta-blocker use } \\
\cline { 2 - 3 } & No (n=868) & Yes (n=185) \\
\hline Underweight & $55(6 \%)$ & $6(3 \%)$ \\
Normal & $363(42 \%)$ & $59(32 \%)$ \\
Overweight and obese & $450(52 \%)$ & $120(65 \%)$ \\
\hline
\end{tabular}

* Data are shown as No. (\%) 
TABLE 3. Binary logistic regression analysis on body mass index status*

\begin{tabular}{lccccccc}
\hline & B & Standard error & Wald & df & P value & Exp(B) & 95\% CI for Exp(B) \\
\hline Age & -0.020 & 0.009 & 5.289 & 1 & 0.021 & 0.980 & $0.963-0.997$ \\
Beta-blockers & 0.558 & 0.172 & 10.481 & 1 & 0.001 & 1.747 & $1.246-2.448$ \\
Insulin & 1.130 & 0.670 & 2.842 & 1 & 0.092 & 3.095 & $0.832-11.510$ \\
Sulfonylurea & 0.032 & 0.276 & 0.013 & 1 & 0.908 & 1.033 & $0.601-1.773$ \\
Loop diuretics & 1.180 & 0.441 & 7.165 & 1 & 0.007 & 3.256 & $1.372-7.727$ \\
Antidepressants & 0.288 & 0.528 & 0.297 & 1 & 0.585 & 1.334 & $0.474-3.758$ \\
Metformin & -0.064 & 0.206 & 0.096 & 1 & 0.756 & 0.938 & $0.627-1.404$ \\
Constant & 1.597 & 0.684 & 5.457 & 1 & 0.019 & 4.938 & \\
\hline
\end{tabular}

Abbreviations: $95 \% \mathrm{Cl}=95 \%$ confidence interval; $\mathrm{df}=$ degrees of freedom; $\mathrm{SE}=$ standard error

* Body mass index status as a binary variable: normal and underweight vs overweight and obese. A few remaining drug groups were not included in this regression analysis because of the low number of patients taking them ( $<10$ out of I053). For details, please refer to Table I. Omnibus tests of model coefficients: for step, block, model, Chi squared=27.345, $d f=7, \mathrm{P}<0.00$ I. Predicted value of the dependent variable based on the full logistic regression model is $55.3 \%$

TABLE 4. Body mass index distribution among older Chinese adults taking different beta-blockers*

\begin{tabular}{|c|c|c|c|c|c|c|c|c|c|c|c|c|c|c|}
\hline & \multicolumn{4}{|c|}{ Total population $(n=1053)$} & \multirow{2}{*}{$\begin{array}{c}P \\
\text { value }\end{array}$} & \multicolumn{4}{|c|}{ Hypertensive participants $(n=626)$} & \multirow{2}{*}{$\begin{array}{c}\mathbf{P} \\
\text { value }\end{array}$} & \multicolumn{4}{|c|}{ Normotensive participants $(n=427)$} \\
\hline & $\begin{array}{l}\text { Under- } \\
\text { weight }\end{array}$ & Normal & $\begin{array}{c}\text { Over- } \\
\text { weight }\end{array}$ & Obese & & $\begin{array}{l}\text { Under- } \\
\text { weight }\end{array}$ & Normal & $\begin{array}{c}\text { Over- } \\
\text { weight }\end{array}$ & Obese & & $\begin{array}{l}\text { Under- } \\
\text { weight }\end{array}$ & Normal & $\begin{array}{c}\text { Over- } \\
\text { weight }\end{array}$ & Obese \\
\hline $\begin{array}{l}\text { No beta- } \\
\text { blockers }\end{array}$ & $55(6 \%)$ & $363(42 \%)$ & $171(20 \%)$ & 279 (32\%) & - & $18(4 \%)$ & $164(37 \%)$ & $96(21 \%)$ & $173(38 \%)$ & - & 37 (9\%) & 199 (48\%) & $75(18 \%)$ & $106(25 \%)$ \\
\hline Atenolol & $1(1 \%)$ & $22(30 \%)$ & $8(11 \%)$ & $43(58 \%)$ & $<0.001$ & $1(1 \%)$ & $21(29 \%)$ & $8(11 \%)$ & $43(59 \%)$ & 0.009 & 0 & $1(100 \%)$ & 0 & 0 \\
\hline Metoprolol & $4(4 \%)$ & 32 (33\%) & $25(26 \%)$ & $37(38 \%)$ & 0.183 & $2(2 \%)$ & $30(33 \%)$ & $24(26 \%)$ & $35(39 \%)$ & 0.617 & $2(29 \%)$ & 2 (29\%) & $1(14 \%)$ & $2(29 \%)$ \\
\hline Propranolol & $1(11 \%)$ & $4(45 \%)$ & $1(11 \%)$ & 3 (33\%) & 0.880 & 0 & 4 (57\%) & $1(14 \%)$ & 2 (29\%) & 0.700 & $1(50 \%)$ & 0 & 0 & 1 (50\%) \\
\hline Bisoprolol & 0 & $1(25 \%)$ & $1(25 \%)$ & 2 (50\%) & 0.808 & 0 & $1(25 \%)$ & $1(25 \%)$ & 2 (50\%) & 0.926 & 0 & 0 & 0 & 0 \\
\hline
\end{tabular}

* Data are shown as No. (\%) of participants, unless otherwise specified

euvolaemia or prevent volume expansion. ${ }^{26}$ In other words, it makes no significant contribution to alteration of dry body weight, which is used for BMI determination and obesity evaluation. Therefore, despite the above findings, loop diuretics were excluded from our further analysis.

\section{Discussion}

Our study presents preliminary findings regarding the potential real-world impact of beta-blockers on weight, noting the high proportion of communitydwelling older adults using these agents. We found a significant association between obesity/overweight with the use of beta-blockers in older Chinese adults. The difference was largely driven by the strong association between obesity and atenolol (rather than other beta-blockers). This may have important ramifications on therapeutic choice if the association is causal.

The potential mechanisms by which betablockers may induce weight gain include reduction of total energy expenditure (by 5\%-10\%), which may involve (1) decreased resting energy expenditure;
(2) increased feelings of tiredness, with subsequent reduction of non-exercise-associated thermogenesis; (3) inhibition of lipolysis; and (4) enhancement of insulin resistance. ${ }^{27}$

Many studies of Caucasian populations have reported the weight gain effects of beta-blockers, being associated with a mean weight gain of $1.2 \mathrm{~kg}$ (range, $-0.4 \mathrm{~kg}$ to $3.5 \mathrm{~kg}$ ), ${ }^{27}$ which could explain our findings of $2.6 \mathrm{~kg}$ higher mean body weight in people taking beta-blockers (mean body weight of people who did vs did not take beta-blockers: $57.8 \pm 9.7 \mathrm{~kg}$ vs $55.2 \pm 9.8 \mathrm{~kg}$, respectively; $\mathrm{P}=0.002$ respectively), but we do not have longitudinal data to make preversus post-drug commencement comparisons. Several studies have compared impact on weight between selected beta-blockers and alternative antihypertensive medications, ie, atenolol versus captopril, ${ }^{2}$ metoprolol versus thiazide diuretics, ${ }^{3}$ atenolol versus chlorthalidone, ${ }^{4}$ and atenolol versus nifedipine, ${ }^{5}$ with all reporting weight gain (or reduced weight loss) in the beta-blocker treatment group. A long-term follow-up study also reported sustained weight gain in a propranolol treatment group compared with a placebo group. ${ }^{28}$ 
Despite the findings of previous studies, to date, there have been no intraclass head-to-head studies in humans regarding beta-blocker-induced weight gain. The two beta-blockers of note, atenolol and metoprolol, both being $\beta 1$-selective betablockers, seemingly have no plausible cause that could account for such differences between them. Our study suggests that atenolol and metoprolol (the two most commonly used beta-blockers in Hong Kong ${ }^{13,14}$ ) may have different effects on weight. We found a significantly higher BMI and a higher proportion of patients with obesity in those taking atenolol compared with those who did not, especially among those defined as being hypertensive. This difference in obesity was also significant for the comparison with metoprolol. Patients taking metoprolol did not show any significant difference from patients who were not on any beta-blockers.

In our study, the mean difference in BMI between those using atenolol and no beta-blockers was about 1.2. Converting the mean BMI difference in a $60-\mathrm{kg}$ woman reveals a mean body weight difference of $3.1 \mathrm{~kg}$. Whether such a degree of weight gain is clinically significant in light of age-related weight gain is worthwhile to discuss. Indeed, agerelated weight gain is an important factor of concern. According to a study of older Chinese adults, the median weight change from 20 years old to baseline was $11.8 \mathrm{~kg}$ and $11.5 \mathrm{~kg}$ for men and women, respectively. ${ }^{29}$ Another 10-year follow-up study also reported that a modest weight gain $(2.5-5 \mathrm{~kg})$ was not associated with an increase in mortality. ${ }^{30}$ Therefore, a gain of $3.1 \mathrm{~kg}$ alone may not be clinically significant. Yet, such a modest weight gain can be additive to physiological age-related weight gain and contribute to obesity. While age-related weight gain may not be a modifiable factor, the selection of pharmacotherapy is definitely one. Particularly, the use of beta-blockers may not actually be the best therapeutic option for hypertension management. Switching to other firstline agents that have no weight gain effects would reduce the possibilities to become obese.

Given our findings, it is important to note the variable recommendations around the use of betablockers in hypertension management. Although a number of international guidelines advocate the use of beta-blockers in patients with both obesity and hypertension, ${ }^{9-11}$ the 2017 American Heart Association guideline criticised atenolol for its inferior efficacy in treatment of hypertension. ${ }^{6}$ Moreover, a meta-analysis of atenolol versus other antihypertensive treatments also reported higher overall and cardiovascular mortality and more frequent strokes with atenolol treatment. ${ }^{31}$ Given these reservations about atenolol and our findings of higher prevalence of obesity in those taking atenolol, it is uncertain whether atenolol should continue to be the most-used drug for hypertension. This is relevant to many parts of the world, including Hong Kong, where atenolol appears to be the first-line therapy for hypertension in older patients and may be associated with an adverse effect on weight and BMI.

To the best of our knowledge, this is the first study to evaluate the association between BMI and beta-blocker use in a Chinese population. Additionally, this is the first study highlighting the intraclass differences between beta-blockers in terms of possible weight gain effects (as illustrated by the proportion of obesity), specifically in the hypertensive Chinese population. Therefore, our findings have implications for local clinical practice given the high rate of use of beta-blockers, particularly atenolol, in the older adults in Hong Kong, despite guideline recommendations.

In considering this study's findings, it is important to acknowledge some of its limitations. First, given the cross-sectional nature of the study, no temporal or causal relationships can be fully assessed or confirmed. We only found an association between beta-blocker usage and obesity in hypertensive patients. We did not assess weight gain, as the term weight gain has a temporal element that should be validated with duration of drug therapy and weight changes throughout a certain period. Second, there is an issue with 'confounding by indication': it is possible that some study patients were obese when their antihypertensive therapy was initiated and, consequently, their physicians elected to use beta-blockers, given the recommendation by the few international consensuses and guidelines. ${ }^{9-12}$ However, since this was a post-hoc analysis based on a cross-sectional study, it is difficult to figure out the temporal sequence-whether beta-blockers were initiated because the patients were obese, or the patients became obese after taking beta-blockers. Third, the results were subject to selection bias because (a) study participation was voluntary, likely representing those who were more physically and/or socially active, and (b) those who were home-bound or had limited access to outdoor environments were not available for inclusion. Third, although the selection criteria were not designed in favour of women, the greater participation of women in our study is common in community-based investigations in Hong Kong, ${ }^{32-37}$ probably reflecting their greater participation in community-based and healthrelated activities. ${ }^{32,33}$ Although the self-reported diagnoses of hypertension were verified against the medication profiles, it is possible that beta-blockers were prescribed for an alternative indication, such as ischaemic heart disease.

\section{Conclusion}

Our study has reported a high proportion of beta-blocker use among Hong Kong older adults 
with hypertension. Beta-blocker users, and more specifically atenolol users, have a significantly higher BMI, as well as a higher propensity towards obesity compared with non-users. Our results can remind clinicians of the possibility that betablockers, particularly atenolol, may worsen weight control in hypertensive patients with obesity or cause significant weight gain in those who are not yet obese. Our findings taken together with other guideline reservations cast doubt on whether betablockers, particularly atenolol, should be the major drug prescribed to older adults with hypertension.

\section{Author contributions}

All authors contributed to the concept of study, acquisition and analysis of data, wrote the article, and had critical revision for important intellectual content. All authors had full access to the data, contributed to the study, approved the final version for publication, and take responsibility for its accuracy and integrity.

\section{Conflicts of interest}

All authors have disclosed no conflicts of interest.

\section{Funding/support}

This research received no specific grant from any funding agency in the public, commercial, or not-for-profit sectors.

\section{Ethics approval}

The study was approved by the Survey and Behavioural Research Ethics Committee of The Chinese University of Hong Kong (Ref 14610518) and was conducted in accordance with the Declaration of Helsinki. Written informed consent was obtained from all study participants. Confidentiality agreement forms were signed by all data collectors.

\section{References}

1. World Health Organization. A global brief on hypertension: silent killer, global public health crisis. Available from: http://www.who.int/cardiovascular_diseases/publications/ global_brief_hypertension/en. Accessed 5 Mar 2019.

2. UK Prospective Diabetes Study Group. Efficacy of atenolol and captopril in reducing risk of macrovascular and microvascular complications in type 2 diabetes: UKPDS 39. BMJ 1998;317:713-20.

3. Wikstrand J, Warnold I, Olsson G, Tuomilehto J, Elmfeldt D, Berglund G. Primary prevention with metoprolol in patients with hypertension. Mortality results from the MAPHY study. JAMA 1988;259:1976-82.

4. Davis BR, Oberman A, Blaufox MD, et al. Effect of antihypertensive therapy on weight loss. The Trial of Antihypertensive Interventions and Management Research Group. Hypertension 1992;19:393-9.

5. Houston MC, Olafsson L, Burger MC. Effects of nifedipine GITS and atenolol monotherapy on serum lipids, blood pressure, heart rate, and weight in mild to moderate hypertension. Angiology 1991;42:681-90.

6. Whelton PK, Carey RM, Aronow WS, et al. 2017 ACC/ AHA/AAPA/ABC/ACPM/AGS/APhA/ASH/ASPC/ NMA/PCNA guideline for the prevention, detection, evaluation, and management of high blood pressure in adults: a report of the American College of Cardiology/ American Heart Association Task Force on Clinical Practice Guidelines. J Am Coll Cardiol 2018;71:e127-248.

7. National Institute of Health and Care Excellence. Hypertension in adults: diagnosis and management (Clinical Guideline 127). Available from: https://www.nice. org.uk/guidance/cg127. Accessed 5 Mar 2019.

8. National Heart Foundation of Australia. Guideline for diagnosis and management of hypertension in adults2016. Melbourne: National Heart Foundation of Australia; 2016.

9. Williams B, Mancia G, Spiering W, et al. 2018 ESC/ESH Guidelines for the management of arterial hypertension. Eur Heart J 2018;39:3021-104.

10. Jordan J, Yumuk V, Schlaich M, et al. Joint statement of the European Association for the Study of Obesity and the European Society of Hypertension: obesity and difficult to treat arterial hypertension. J Hypertens 2012;30:104755.

11. Landsberg L, Aronne AJ, Beilin LJ, et al. Obesity-related hypertension: pathogenesis, cardiovascular risk, and treatment: a position paper of The Obesity Society and the American Society of Hypertension. J Clin Hypertens (Greenwich) 2013;15:14-33.

12. Dentali F, Sharma AM, Douketis JD. Management of hypertension in overweight and obese patients: a practical guide for clinicians. Curr Hypertens Rep 2005;7:330-6.

13. Wong MC, Tam WW, Cheung CS, et al. Antihypertensive prescriptions over a 10-year period in a large Chinese population. Am J Hypertens 2013;26:931-8.

14. Wong MC, Tam WW, Wang HH, et al. Predictors of the incidence of all-cause mortality and deaths due to diabetes and renal diseases among patients newly prescribed antihypertensive agents: a cohort study. Int J Cardiol 2013;168:4705-10.

15. Wong MC, Tam WW, Cheung CS, et al. Initial antihypertensive prescription and switching: a 5 year cohort study from 250,851 patients. PLoS One 2013;8:e53625.

16. Mathus-Vliegen EM. Obesity and the elderly. J Clin Gastroenterol 2012;46:533-44.

17. Han TS, Tajar A, Lean ME. Obesity and weight management in the elderly. Br Med Bull 2011;97:169-96.

18. Zamboni M, Mazzali G, Zoico E, et al. Health consequences of obesity in the elderly: a review of four unresolved questions. Int J Obes (Lond) 2005;29:1011-29.

19. Bui AL, Horwich TB, Fonarow GC. Epidemiology and risk profile of heart failure. Nat Rev Cardiol 2011;8:30-41.

20. Klonoff DC. The increasing incidence of diabetes in the 21st century. J Diabetes Sci Technol 2009;3:1-2.

21. Hajjar I, Kotchen JM, Kotchen TA. Hypertension: trends in prevalence, incidence, and control. Annu Rev Public Health 2006;27:465-90.

22. Savarese G, Lund LH. Global public health burden of heart failure. Card Fail Rev 2017;3:7-11.

23. Leung K, Fong W, Lau PS, et al. Impact of dining out and food intake pattern on atrial fibrillation prevalence in Hong Kong Chinese elders. Value Health 2018;21:S57.

24. WHO Expert Consultation. Appropriate body-mass index for Asian populations and its implications for policy and intervention strategies. Lancet 2004;363:157-63.

25. Coleman A, Freeman P, Steel S, Shennan A. Validation of the Omron 705IT (HEM-759-E) oscillometric blood pressure 
monitoring device according to the British Hypertension Society protocol. Blood Press Monit 2006;11:27-32.

26. Casu G, Merella P. Diuretic therapy in heart failurecurrent approaches. Eur Cardiol 2015;10:42-7.

27. Pischon T, Sharma AM. Use of beta-blockers in obesity hypertension: potential role of weight gain. Obes Rev 2001;2:275-80.

28. Rössner S, Taylor CL, Byington RP, Furberg CD. Long term propranolol treatment and changes in body weight after myocardial infarction. BMJ 1990;300:902-3.

29. Zhu J, Xiang YB, Cai H, et al. Associations of obesity and weight change with physical and mental impairments in elderly Chinese people. Maturitas 2018;108:77-83.

30. Park SY, Wilkens LR, Maskarinec G, Haiman CA, Kolonel LN, Marchand LL. Weight change in older adults and mortality: the Multiethnic Cohort Study. Int J Obes (Lond) 2018;42:205-12.

31. Carlberg B, Samuelsson O, Lindholm LH. Atenolol in hypertension: is it a wise choice? Lancet 2004;364:1684-9.

32. Leung GT, Leung KF, Lam LC. Classification of late-life leisure activities among elderly Chinese in Hong Kong. East Asian Arch Psychiatry 2011;21:123-7.

33. Woo J, Mak B, Yeung F. Age-friendly primary health care: an assessment of current service provision for older adults in Hong Kong. Health Serv Insights 2013;6:69-77.

34. Su EX, Lin YQ, Zhang SL, Leung GT, Lam LC, Chiu HF. Physical activity and cognitive function of community Chinese elderly in Hong Kong (HK) and Guangzhou (GZ). Int Psychogeriatr 2015;27:959-66.

35. Kwok T, Wong A, Chan G, et al. Effectiveness of cognitive training for Chinese elderly in Hong Kong. Clin Interv Aging 2013;8:213-9.

36. Shen C, Schooling CM, Chan WM, Lee SY, Leung GM, Lam TH. Self-reported diabetes and mortality in a prospective Chinese elderly cohort study in Hong Kong. Prev Med 2014;64:20-6.

37. Cheung MC, Ting W, Chan LY, et al. Leisure participation and health-related quality of life of community dwelling elders in Hong Kong. Asian J Gerontology Geriatr 2009;4:15-23. 